\title{
Influence of Isolation Technique on the Survival of Resin- Modified Glass-Ionomer Restorations in Primary Molars: A 9- Months Randomized Controlled Trial
}

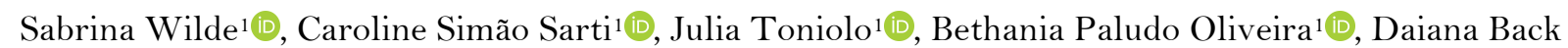
Gouvea $^{1}\left(\mathbb{D}\right.$, Nicole Marchioro dos Santos ${ }^{1}\left[\right.$, Maria Luiza Vieira Borges ${ }^{\circledR}$, Jonas Almeida Rodrigues ${ }^{1}$

${ }^{1}$ Pediatric Dentistry Division, School of Dentistry, Federal University of Rio Grande do Sul, Porto Alegre, RS, Brazil.

Correspondence: Jonas Almeida Rodrigues, Pediatric Dentistry Division, Faculty of Dentistry, Federal University of Rio Grande do Sul, Rua Ramiro Barcelos, 2492, Rio Branco, Porto Alegre, RS, Brazil. 90035-003. E-mail: jorodrigues@ufrgs.br

Academic Editor: Burak Buldur

Received: 02 September 2020 / Review: 06 November 2020 / Accepted: 23 November 2020

How to cite: Wilde S, Sarti CS, Toniolo J, Oliveira BP, Gouvea DB, Santos NM, et al. Influence of isolation technique on the survival of resin-modified glass-ionomer restorations in primary molars: a 9-months randomized controlled trial. Pesqui Bras Odontopediatria Clín Integr. 2021; 21 :e0195. https://doi.org/10.1590/pboci.2021.061

\begin{abstract}
Objective: To compare the survival of occlusal and occlusal-proximal restorations performed with resinmodified glass-ionomer cement (RMGIC) in deciduous molars using rubber dam and cotton rolls isolation. Material and Methods: Ninety-two patients were included and 200 deciduous molars with cavitated occlusal or occlusoproximal dentin caries lesions were randomized into two groups: cotton rolls $(\mathrm{n}=100)$ and rubber dam $(n=100)$ and RMGIC restorations were placed. At baseline and in the follow-up visit, presence, severity and activity of caries lesions were registered. Two independent, blinded examiners evaluated the treated teeth clinically using the USPHS criteria and radiographically after 9 months. Descriptive analysis, survival curve (log-rank test) and Cox regression were performed to assess risk factors related to failure. Results: Out of the 179 teeth (92 cotton rolls group and 87 rubber dam group) evaluated at 9-month follow-up period. No lesion progression was observed radiographically. The overall treatment success rate was $85.47 \%$ ( $83.47 \%$ for cotton rolls and 87.35 rubber dam group). No significant difference between isolation methods was observed in the log-rank test $(p=0.16)$. Cox regression showed no risk factors related to failure. Conclusion: No difference was found in the survival of occlusal and occlusalproximal restorations performed with RMGIC in deciduous molars using a rubber dam and cotton rolls isolation after a 9-month follow-up period.
\end{abstract}

Keywords: Dental Caries; Survival Analysis; Deciduous Tooth; Rubber Dams. 


\section{Introduction}

Restorative treatments are performed to aid biofilm control, protect the pulp-dentin complex, and restore the integrity of the dental structure, thereby recovering functional and esthetic needs and causing no unnecessary damage. Carious tissue removal ensures the conditions for a long-lasting restoration, preserves remineralizable tissue, maintains pulp vitality, and achieves an adequate seal [1]. Complete carious tissue removal of deep carious lesions has been proven to increase the occurrence of pulpal exposure and postoperative pulpal symptoms compared with selective carious tissue removal [2,3]. Selective caries removal (SCR) is a contemporary approach for the restorative treatment of deep caries lesions in dentin, showing good results along time [1,4]. In deep lesions, SCR of soft dentin has been recommended to avoid pulp exposure and allow the placement of a durable restoration [1]. Despite the benefits of SCR, evidence regarding survival of restoration in deciduous teeth is limited [2].

After SCR, the restorative technique with composite resin recommends using rubber dam isolation to reduce bacterial contamination and control humidity [5]. The isolation is made with rubber dam, dental clamp and bow and usually is necessary to perform some kind of anesthetic technique to reduce the discomfort [6].

Both rubber dam and cotton rolls are currently used in dentistry to isolate the treatment field and to exclude moisture. There are advantages and disadvantages associated with each method from the different points of view of person and dentist. Moreover, several randomized controlled trials have been conducted to determine whether the use of a rubber dam for restorative treatments influences the treatment outcomes [7-9].

In addition to the type of isolation, the success of treatment also depends on the restorative material used. A systematic meta-analysis review [10] assessed the survival of restorations performed with different restorative materials after RSTC. There was no statistically significant difference between composite resin and resin-modified glass-ionomer cement (RMGIC), which had higher survival rates than conventional (chemically activated) glass ionomer cement.

Because of its ease of use and shorter clinical time, when using RMGIC, rubber dam isolation may not be required, using only cottons rolls isolations and saliva ejector [11]. Besides, the manufacturer of RMGIC generally recommends the use of isolation; however, any specification is given about rubber dam or cotton rolls. In the study conducted by Carvalho et al. [7], restorations performed under rubber dam and cotton rolls/saliva ejector had similar survival rates, i.e., the use of rubber dam did not increase the longevity of conventional glass-ionomer restorations in deciduous teeth.

Considering deciduous dentition, an extremely important factor is the time taken to perform the procedure, as well as the psychological impact and discomfort that a more invasive treatment may cause [12].

Therefore, the aim of this randomized controlled clinical trial was to compare the survival of occlusal and occlusal-proximal restorations performed with RMGIC in deciduous molars using rubber dam and cotton rolls isolation. Besides, this study assessed clinic and radiographic arrestment of lesions as well as pulp vitality of restored teeth. The null hypothesis tested was that rubber dam isolation does not increase the survival rates of RMGIC restorations of dentin caries lesions in deciduous molars.

\section{Material and Methods}

Sample Size

The sample size calculation was performed based on a previous study [7] performed in deciduous teeth that evaluated the survival rates of occlusal-proximal atraumatic restorative treatment (ART) restorations placed in deciduous molars using cotton rolls or rubber dam as isolation methods. A sample of 48 
teeth was defined per group (96 total teeth), considering a superiority design, with a power of $80 \%$ and level of significance of $5 \%$, accepting a success rate of $61.9 \%$ in the cotton rolls isolation group and $80 \%$ in the rubber dam isolation group with a $30 \%$ sample loss rate and $20 \%$ of cluster effect.

\section{Participants and Recruitment}

This single-blind randomized controlled clinical trial was reported according to the CONSORT statement. The treatments were carried out at the Pediatric Clinic in the Federal University of Rio Grande do Sul, School of Dentistry, Porto Alegre, Brazil, after the Local Research Ethics Committee approval (CAAE: 80465617.6.0000.5347). A written informed consent was obtained from all participants and their parents or legal guardians (REBEC Register Number: RBR-8HCG2C).

Between December 2018 and May 2019, 197 children (1576 teeth) aged between 3 to 9 years old seeking dental treatment were evaluated, and 92 (mean age $=6)$ were included after a complete anamnesis and clinical and radiographic examination. Standardized modified interproximal radiographs were taken to evaluate the pulp and periapical condition. Visible plaque index (VPI), gingival bleeding index (GBI) and clinical examinations were performed by two operators (NMS and CSS) who were trained and calibrated according to the International Caries Detection System (ICDAS) and for caries activity according to visual-tactile criteria proposed by Nyvad and Baelum [13]. The kappa inter-examiner value for clinical examinations was 0,80 and the intra-examiner values were 0,69 (CSS) and 0,83 (NMS).

Inclusion criteria consisted of patients with at least one cavitated occlusal or occlusoproximal carious lesion in a deciduous molar with a radiographically measurable depth in the outer or inner half of the dentin [14] referred to restorative treatment. The included teeth should also have at least two-thirds of the root visible in the radiography. Patients with spontaneous pain, fistula, and mobility not compatible with the root resorption period and advanced rhizolysis were not included. During the study, patients who did not want to participate any longer or who moved out of the city were excluded.

\section{Randomization and Allocation Confidentiality}

A list of random numbers generated using the site www.randomization.com was used for the randomization process in which the tooth was the unit. The list was in possession of a third researcher not involved with the clinical assessment or with data analysis and was revealed to the operators only when the child was already in the chair. The randomization unit was the tooth, so in case of a child needs more than one restoration, another appointment was scheduled.

\section{Clinical Exams and Interventions}

All patients received prophylaxis prior to treatment and oral hygiene guidance with toothbrush and floss, fluoride dentifrice (1100 ppm F), and dietary counselling. The treatments were performed by two paediatric specialist dentists (CSS and NMS) following the protocol in which the tooth was allocated, as follows:

- Rubber dam group (test): After local anesthesia, the tooth was isolated using rubber dam, Ostby arch, dental floss, and appropriate clamp. The selective caries removal was performed using a slow, new, sterile, and round steel bur, according to the clinical hardness criteria. As proposed by the manufacturer, the phosphoric acid (Super Etch 37\%, SDI, Victoria, Australia) was applied to the prepared surfaces and left in the cavity for 10 seconds, then rinsed thoroughly with water and the cavity gently air-dried. For 
occlusoproximal cavities, a Tofflemire matrix band $\mathrm{n}^{\circ} 1$ with a universal Tofflemire matrix retainer was placed (Tofflemire, New York, USA). The restoration was performed with the RMGIC powder/liquid (RIVA Light Cure - SDI, Victoria, Australia) with an insertion spatula, following the manufacturer's instructions. The restoration was light-cured for $20 \mathrm{~s}$ using an LED light-curing unit (Emitter C Schuster - intensity of $\left.1250 \mathrm{~mW} / \mathrm{cm}^{2}\right)$. For cavities deeper than $1.8 \mathrm{~mm}$, the material was applied in two layers. Finishing and polishing were carried out with diamond drills and silicone tips.

- Cotton rolls group (control): The tooth was isolated using cotton rolls together with suction to remove the excess of saliva. The selective caries removal and restorative procedure were performed exactly as done for test group. In both groups, the restorations were performed with four hands.

Follow-up Assessment and Radiographic Analysis

Patients returned after 9 months. In this follow-up visit, VPI, GBI were performed and after prophylaxis with Robinson bristle brushes, the dental caries was assessed according to ICDAS scores and caries activity was assessed according to the visual-tactile criteria proposed by Nyvad and Baelum [13]. Two blinded trained and calibrated examiners (JT and SW) evaluated the treated teeth using the USPHS criteria [15] (Table 1). Based on the USPHS criteria, considering the restorative material, Criteria I (retention), III (marginal integrity), VII (postoperative sensitivity according to patient), and IX (secondary caries) were used to evaluate the survival of the treatments. The kappa inter-examiner value was 0.75 and the intra-examiner values were $0.89(\mathrm{JT})$ and $0.92(\mathrm{SW})$.

Table 1. Summary of USPHS criteria [15].

\begin{tabular}{|c|c|c|c|}
\hline Criteria & Test Procedure & USPHS Score & \\
\hline I. Retention & $\begin{array}{l}\text { Visual inspection with } \\
\text { mirror at } 18 \text { inches }\end{array}$ & $\begin{array}{l}\text { Complete retention of the restoration } \\
\text { Mobilization of the restoration, still present } \\
\text { Loss of the restoration }\end{array}$ & $\begin{array}{l}\text { Alpha } \\
\text { Bravo } \\
\text { Charlie* }\end{array}$ \\
\hline III. Marginal Integrity & $\begin{array}{l}\text { Visual inspection with } \\
\text { mirror at } 18 \text { inches }\end{array}$ & $\begin{array}{l}\text { Absence of discrepancy at probing } \\
\text { Presence of discrepancy at probing, without dentin exposure } \\
\text { Probe penetrates in the discrepancy at probing, with dentin } \\
\text { exposure }\end{array}$ & $\begin{array}{l}\text { Alpha } \\
\text { Bravo } \\
\text { Charlie* }\end{array}$ \\
\hline $\begin{array}{l}\text { VII. Postoperative } \\
\text { Sensitivity }\end{array}$ & Ask patients & $\begin{array}{l}\text { Absence of the dentinal hypersensitivity } \\
\text { Presence of mild and transient hypersensitivity } \\
\text { Presence of strong and intolerable hypersensitivity }\end{array}$ & $\begin{array}{l}\text { Alpha } \\
\text { Bravo } \\
\text { Charlie* }\end{array}$ \\
\hline IX. Secondary Caries & $\begin{array}{l}\text { Visual inspection with } \\
\text { explorer and mirror, if } \\
\text { needed }\end{array}$ & $\begin{array}{l}\text { No evidence of caries } \\
\text { Evidence of caries along the marginal of the restoration }\end{array}$ & $\begin{array}{l}\text { Alpha } \\
\text { Bravo* }\end{array}$ \\
\hline
\end{tabular}

A standardized modified interproximal radiograph was followed up for 9 months. Lesions were visually classified by a senior researcher (JAR) as 'progressed' or 'arrested' in darkroom conditions on the negatoscope. The examiner was blind with regard to groups. No important changes to methods were made after trial commencement.

\section{Outcome}

The main outcome variable was the integrity of the intervention material (longevity of the material according to USPHS criteria) and, secondarily, caries arrestment status (absence or presence). Criteria I (C), VII (C), and IX (B) were considered as clinical failure. In these cases, the teeth were submitted to the appropriate treatment (restoration, endodontic, or extraction) and the failure was registered. In cases where a failure occurred in the margin of the restoration with exposure of dentin (III - C), restoration was repaired 
according to the group in which the tooth was allocated and continued to be evaluated. Teeth showing radiographic carious lesion progression were submitted to appropriate treatment (restoration, endodontic, or extraction) and the failure was registered.

\section{Statistical Analysis}

Clinical failures related to treatments were submitted to multivariate logistic regression with shared fragility (Cox regression). Median was used to dichotomize age and dmft. Cut point for VPI and GBI as set at $10 \%$, according to Trombelli et al. [16]. Variables showing an association with p-values below or equal to 0.20 in the univariate model were submitted to multivariate analysis. The Kaplan-Meier method was used to analyze differences in treatment survival rates between groups. The log-rank test was used to compare group success rates. A paired t-test was performed to analyze inter- and intra-group VPI and GBI. All analyzes were performed considering a significance level of 5\%, using appropriate statistical software (IBM SPSS 20.0).

\section{Results}

Ninety-two children were included (mean age $6.8 \pm 1.37 ; 39$ males (42.4\%) and 53 females (57.6\%). A total of 200 dentin cavitated lesions were treated ( 100 for each group). No difference was observed between the sample characteristics (except for dmft and location of the lesion in the arch) as described in Table 2.

Table 2. Sample characteristics according to treatment groups at baseline.

\begin{tabular}{|c|c|c|c|}
\hline \multirow[b]{2}{*}{ Variables } & \multicolumn{2}{|c|}{ Treatment } & \multirow[b]{2}{*}{ p-value } \\
\hline & $\begin{array}{c}\text { Cotton Rolls } \\
\mathrm{N}\end{array}$ & $\begin{array}{c}\text { Rubber Dam } \\
\mathrm{N}\end{array}$ & \\
\hline \multicolumn{4}{|c|}{ Referring to the Patient } \\
\hline \multicolumn{4}{|l|}{ Gender } \\
\hline Male & 36 & 34 & 0.55 \\
\hline Female & 56 & 53 & \\
\hline \multicolumn{4}{|l|}{ Visible Plaque Index } \\
\hline$<10 \%$ & 08 & 14 & 0.10 \\
\hline$>11 \%$ & 84 & 73 & \\
\hline \multicolumn{4}{|c|}{ Gingival Bleeding Index } \\
\hline$<10 \%$ & 40 & 36 & 0.44 \\
\hline$>11 \%$ & 52 & 51 & \\
\hline \multicolumn{4}{|l|}{$\mathrm{dmft}$} \\
\hline$<3$ & 43 & 27 & $0.02 *$ \\
\hline$>4$ & 49 & 60 & \\
\hline \multicolumn{4}{|l|}{ Age (Years) } \\
\hline$<6.6$ & 43 & 44 & 0.35 \\
\hline$>6.7$ & 49 & 43 & \\
\hline \multicolumn{4}{|l|}{ Location of the Lesion } \\
\hline \multicolumn{4}{|l|}{ Restored Surfaces } \\
\hline 1 Surface & 57 & 55 & 0.49 \\
\hline 2 Surfaces & 35 & 32 & \\
\hline \multicolumn{4}{|l|}{ Arch } \\
\hline Upper & 39 & 49 & $0.04 *$ \\
\hline Lower & 53 & 38 & \\
\hline \multicolumn{4}{|l|}{ Side } \\
\hline Right & 49 & 44 & 0.41 \\
\hline Left & 43 & 43 & \\
\hline \multicolumn{4}{|l|}{ Molar } \\
\hline 1st Molar & 39 & 36 & 0.50 \\
\hline 2nd Molar & 53 & 51 & \\
\hline
\end{tabular}


At the 9-month follow-up, 77 children (179 teeth; 92 cotton rolls and 87 rubber dam) were clinically and radiographically evaluated (89.5\% of baseline). The number of children, teeth allocated in each group, and drop-outs at the evaluation period can be observed in the flow diagram (Figure 1).

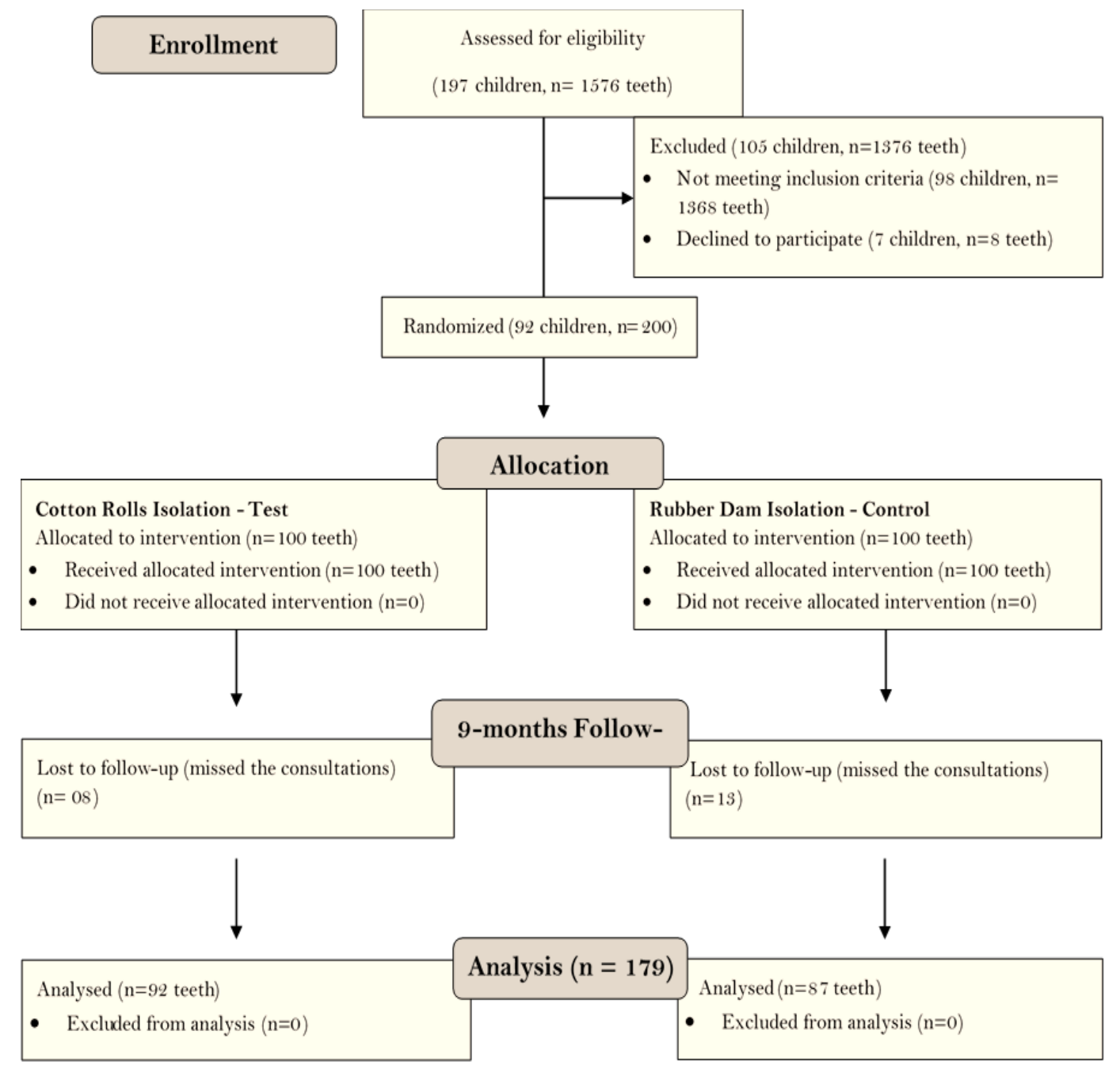

Figure 1. CONSORT Flow Diagram.

The overall treatment success rate was $85.47 \%$ ( $83.47 \%$ for the cotton rolls group and $87.35 \%$ for the rubber dam group). Kaplan-Meier survival curve is presented in Figure 2. The log-rank test was not significant $(\mathrm{p}=0.16)$. No lesion progression was observed radiographically.

According to USPHS criteria, there were 4 failures that occurred in the cotton rolls group and 5 failures in the rubber dam group according to Criterion I (retention). Three failures occurred in the cotton rolls group, and 1 failure occurred in the rubber dam group, according to Criterion III (marginal integrity). Seven failures occurred in the cotton rolls group and 3 failures in the rubber dam group, according to Criterion IX (secondary caries). Postoperative sensitivity (Criterion VII) was not reported by any child of both groups.

Cox regression was used to assess the risk factors related to failure (isolation method; age; gender; dmf-t; teeth; location of the lesion, VPI and GBI). There was no significant association with the risk factors analyzed (Table 3 ). 


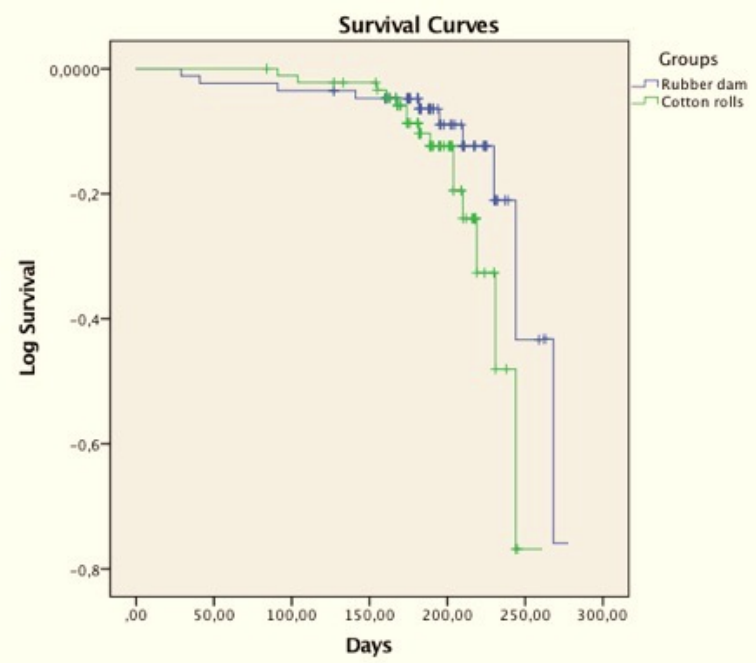

Figure 2. Kaplan-Meier survival curves.

Table 3. Univariate ${ }^{\mathrm{a}}$ and multivariate ${ }^{\mathrm{b}}$ Cox Regression.

\begin{tabular}{|c|c|c|c|c|c|}
\hline Risk Factors & Categories & $\begin{array}{c}\text { Hazard Ratio }^{a} \\
\text { (IC } 95 \%)\end{array}$ & p-value & $\begin{array}{c}\text { Hazard Ratio }^{\text {b }} \\
\text { (IC 95\%) }\end{array}$ & p-value \\
\hline \multirow[t]{2}{*}{ Gender } & Male & 1.00 & 0.97 & - & - \\
\hline & Female & $1.01(0.44-2.32)$ & & & \\
\hline \multirow{2}{*}{ Age (years) } & $<6.6$ & 1.00 & 0.79 & - & - \\
\hline & $>6.7$ & $0.90(0.40-2.01)$ & & & \\
\hline \multirow[t]{2}{*}{ Isolation Method } & Rubber Dam & 1.00 & 0.17 & 1.00 & 0.14 \\
\hline & Cotton Rolls & $0.56(0.24-1.28)$ & & $0.53(0.23-1.23)$ & \\
\hline \multirow[t]{2}{*}{ Restored Surfaces } & 1 Surface & 1.00 & 0.16 & 1.00 & 0.40 \\
\hline & 2 Surfaces & $0.57(0.26-1.26)$ & & $0.68(0.28-1.65)$ & \\
\hline \multirow[t]{2}{*}{ Arch } & Upper & 1.00 & 0.88 & - & - \\
\hline & Lower & $1.06(0.47-2.39)$ & & & \\
\hline \multirow[t]{2}{*}{ Right/Left } & Right & 1.00 & 0.62 & - & - \\
\hline & Left & $1.06(0.36-1.84)$ & & & \\
\hline \multirow[t]{2}{*}{ Molar } & 1st Molar & 1.00 & 0.14 & 1.00 & 0.27 \\
\hline & 2nd Molar & $1.81(0.82-3.98)$ & & $1.62(0.28-1.83)$ & \\
\hline \multirow[t]{2}{*}{ Visible Plaque Index } & $<10 \%$ & 1.00 & 0.28 & - & - \\
\hline & $>11 \%$ & $1.65(0.65-4.19)$ & & & \\
\hline \multirow[t]{2}{*}{ Gingival Bleeding Index } & $<10 \%$ & 1.00 & 0.34 & - & - \\
\hline & $>11 \%$ & $1.48(0.66-3.31)$ & & & \\
\hline \multirow[t]{2}{*}{$\mathrm{dmft}$} & $<3$ & 1.00 & 0.97 & - & - \\
\hline & $>4$ & $0.98(0.43-2.26)$ & & & \\
\hline
\end{tabular}

There was a statistically significant improvement in the GBI values (t-test; $p=0.00$ ). The same test also pointed out the decrease on VPI and GBI values during the 9 months for each group (rubber dam and cotton rolls). There was a statistically significant improvement for GBI in the rubber dam group ( $p=0.00)$. No important harms or unintended effects were observed in both groups (Table 4).

Table 4. Changes regarding VPI and GBI values.

\begin{tabular}{|c|c|c|c|c|c|c|c|}
\hline & \multirow{3}{*}{ Variables } & \multicolumn{5}{|c|}{ Paired Differences } & \multirow{3}{*}{ p-value } \\
\hline & & \multirow[t]{2}{*}{ Mean } & \multirow[t]{2}{*}{ SD } & \multirow{2}{*}{$\begin{array}{c}\text { Std. Error } \\
\text { Mean }\end{array}$} & \multicolumn{2}{|c|}{$95 \%$ CI of the Difference } & \\
\hline & & & & & Lower & Upper & \\
\hline VPI & VPI Initial $-6 \mathrm{~m}$ & -0.05 & 0.37 & 0.02 & -0.11 & 0.00 & 0.05 \\
\hline GBI & GBI Initial $-6 \mathrm{~m}$ & -0.17 & 0.65 & 0.04 & -0.26 & -0.07 & $0.00^{*}$ \\
\hline Dmft & Dmft Initial $-6 \mathrm{~m}$ & -0.04 & 0.40 & 0.03 & -0.10 & 0.01 & 0.14 \\
\hline
\end{tabular}




\begin{tabular}{llccccccc} 
Cotton Rolls & VPI Initial $-6 \mathrm{~m}$ & -0.01 & 0.34 & 0.03 & -0.08 & 0.06 & 0.76 \\
& GBI Initial $-6 \mathrm{~m}$ & -0.15 & 0.67 & 0.07 & -0.29 & -0.01 & 0.03 \\
& Dmft Initial $-6 \mathrm{~m}$ & -0.08 & 0.43 & 0.04 & -0.17 & 0.00 & 0.05 \\
\multirow{3}{*}{ Rubber Dam } & VPI Initial $-6 \mathrm{~m}$ & -0.10 & 0.40 & 0.04 & -0.19 & -0.01 & 0.01 \\
& GBI Initial $-6 \mathrm{~m}$ & -0.19 & 0.62 & 0.06 & -0.32 & -0.06 & $0.00 *$ \\
& Dmft Initial $-6 \mathrm{~m}$ & 0.00 & 0.37 & 0.04 & -0.08 & 0.08 & 1.00 \\
\hline *t-test. & & & & & &
\end{tabular}

\section{Discussion}

This is the first randomized controlled clinical study in deciduous molars that tested isolation methods for RMGIC restorations. This study showed that the use of rubber dam isolation did not increase the survival rates of RMGIC restorations nor did not show an association to the arrestment of dentin cavitated caries lesions. These findings are in accordance with the study of Carvalho et al. [7], which reported that proximal atraumatic restorative treatment (ART) restorations performed in deciduous molars with rubber dam were not statistically different than with cotton rolls/saliva ejector. Moreover, our results also showed no radiographic lesion progression in both groups.

This clinical trial showed that the survival rate of RMGIC restorations was not influenced by the type of isolation since no statistically significant difference between the groups was found. According to Carvalho et al. [7], saliva contamination is supposed to be one of the causes of the low success rate of occluso-proximal restorations. However, the use of rubber dam isolation to avoid saliva contamination during the ART procedure did not significantly improve the survival rate of occluso-proximal restorations on deciduous teeth. The authors also suggest that the possible contamination by saliva is not the determining factor in the failure of ART occluso-proximal restorations. On the other hand, a study evaluated the influence of relative and absolute isolation on the survival of proximal ART restorations in deciduous molars with three different types of glass ionomer cements (Fuji IX, Ketac Molar Easymix and Ketac Molar Aplicap) [8]. The authors concluded that after two years of follow-up, the survival rate of restorations placed under rubber dam isolation was greater than those performed under relative isolation; however, when comparing the isolation technique and the material used, the survival of the restorations showed no difference [8].

Especially in pediatric dentistry, factors related to the patient can play an important role when considering behavior management. Thus, the survival of the restoration can vary due to different conditions that affect the technique [17,18]. Poor oral hygiene and increased sugar intake are frequent in high-caries risk pediatric patients and can contribute to caries development. As secondary caries or caries adjacent to restorations are subjected to the same factors as primary caries, the difficulty of the dentist or of the patients and their families to change behaviors could contribute to the early failure of restorations in pediatric dentistry. This highlights the need for professionals to work with a health-promoting approach, which should improve treatment longevity [19]. In this study, it was observed that the patients had a significant improvement in the GBI, which is probably linked to the fact that all dental care needs, including non, micro- and invasive treatments, were provided.

In the present study, no primary lesion progression was clinically and radiographically observed in both groups. Concerning failures, the systematic review of Chisini et al. [20] showed that caries near the restoration was the main reason for failures for composite or for glass ionomer materials, suggesting that the release of fluoride by glass-ionomer cement did not affect the longevity of restorations. This data is in accordance with the present study, where the main reason for failure was dental caries adjacent to restorations ( 7 failures occurred in the cotton rolls group and 3 failures in the rubber dam group). Four failures related to 
marginal integrity were observed ( 3 in the cotton rolls group and 1 in the rubber dam group), which were repaired and kept in the sample for follow-up and further analysis. This conservative approach is strongly recommended since it can increase restoration survival without the need for replacement. Considering the involved surface, occlusal-proximal restorations showed similar risk or failure compared to occlusal restorations. However, a longer period of follow-up is needed to stronger this evidence.

Regarding the method of assessing restorations, Wang et al. [21] conducted a systematic review to assess the effects of rubber dam isolation compared with other types of isolation used for direct and indirect restorative treatments in dental patients. Three out of 4 studies reported low survival rates. However, it was not possible to group the results to address this information due to the inconsistent presentation of the data, differences in the restorative treatments performed, different monitoring moments or different criteria used to define 'survival / failure' between them. Other systematic review [10], which assessed the influence of the isolation technique on direct restorations, also reported the inconsistency in the assessment of survival of restorations because the four articles selected for analysis none used the same criteria. This difference in the criteria to determine the success of dental restorations can be considered a problem, as pointed out by Chadwick et al. [22], who considered that inconsistencies in the use of clinical criteria could be an important source of bias in clinical trials. In our study, the USPHS criterion was used to assess the survival rates, which is a criterion able to register important failures in RMGIC restorations (retention, marginal integrity, secondary caries and post-operatory pain).

It is important to highlight that the results of the present clinical trial should be evaluated with caution, given the short time period of follow-up. Besides, the clinical decision must be based not only on the type of isolation but also on the operator's degree of experience, which is probably a related factor in the survival of the restoration. Studies with longer follow-up are needed to assess the survival of restorations.

\section{Conclusion}

No difference was found in the survival of occlusal and occlusal-proximal restorations performed with RMGIC in deciduous molars using rubber dam and cotton rolls isolation after a 9-month follow-up period.

\section{Authors' Contributions}

\begin{tabular}{|c|c|c|}
\hline SW & (i) https://orcid.org/0000-0002-1344-479X & $\begin{array}{l}\text { Conceptualization, Methodology, Formal Analysis, Investigation, Writing - Original Draft and } \\
\text { Writing - Review and Editing. }\end{array}$ \\
\hline CSS & (iD) https://orcid.org/0000-0003-0717-5340 & Conceptualization, Methodology and Writing - Original Draft. \\
\hline JT & (iD) https://orcid.org/0000-0002-7663-5788 & Conceptualization, Methodology and Writing - Review and Editing. \\
\hline $\mathrm{BPO}$ & (iD) https://orcid.org/0000-0003-0883-2613 & Conceptualization, Methodology and Writing - Review and Editing. \\
\hline DBG & (iD) https://orcid.org/o000-0003-1180-9326 & Conceptualization, Methodology and Writing - Review and Editing. \\
\hline NMS & (iD) https://orcid.org/0000-0002-6858-7448 & Conceptualization, Methodology and Writing - Review and Editing. \\
\hline MLVB & (iD) https://orcid.org/0000-0001-5870-6020 & Conceptualization and Methodology. \\
\hline JAR & (iD) https://orcid.org/0000-0001-8887-2329 & $\begin{array}{l}\text { Conceptualization, Methodology, Formal Analysis, Writing - Original Draft, Writing - Review } \\
\text { and Editing and Supervision. }\end{array}$ \\
\hline
\end{tabular}

\section{Financial Support}

This study was financed in part by the Coordenação de Aperfeiçoamento de Pessoal de Nível Superior - Brasil (CAPES) - Finance Code 001 .

\section{Conflict of Interest}

The authors declare no conflicts of interest.

\section{Data Availability}

The data used to support the findings of this study can be made available upon request to the corresponding author. 


\section{References}

[1] Schwendicke F, Frencken JE, Bjørndal, Maltz M, Manton DJ, Ricketts D, et al. Managing carious lesions: Consensus recommendations on carious tissue removal. Adv Dent Res 2016; 28(2):58-67. https://doi.org/10.1177/0022034516639271

[Q] Ricketts D, Lamont T, Innes NPT, Kidd E, Clarkson JE. Operative caries management in adults and children. Cochrane Database Syst Rev 2013; (3):CD003808. https://doi.org/10.1002/14651858.CD003808.pub3

[3] Li T, Zhai X, Song F, Zhu H. Selective versus non- selective removal for dental caries: a systematic review and metaanalysis. Acta Odontol Scand 2018; 76(2):135-40. https://doi.org/10.1080/00016357.2017.1392602

[4] Casagrande L, Bento LW, Dalpian DM, Garcia-Godoy F, de Araujo FB. Indirect pulp treatment in primary teeth: 4year results. Am J Dent 2010; 23(1):34-8.

[5] Cochran MA, Miller CH, Scheldrake MA. The efficacy of the rubber dam as a barrier to the spread of microorganisms during dental treatment. J Am Dent Assoc 1989; 119(1):141-4. https://doi.org/10.142 19/jada.archive.1989.0131

[6] Hill EE, Rubel BS. Do dental educators need to improve their approach to teaching rubber dam use? J Dent Educ 2008; 72(10)1177-81

[7] Carvalho TS, Sampaio FC, Diniz A, Bönecker M, Van Amerongen WE. Two years survival rate of Class II ART restorations in primary molars using two ways to avoid saliva contamination. Int J Paediatr Dent 2010; 20:419-25. https://doi.org/10.1111/j.1365-263X.2010.01060.x

[8] Kemoli AM, Van Amerongen WE, Opinya GN. Short communication: Influence of different isolation methods on the survival of proximal ART restorations in primary molars after two years. Eur Arch Paediatr Dent 2010; 11(3):136-9. https://doi.org/10.1007/BFo3262729

[9] Ma J. Influence of rubber dam isolation on the performance of restorations for teeth wedge-shaped defects. Chinese Community Doctors 2012; 14(309): 164 .

[10] Pires CW, Pedrotti D, Lenzi TL, Soares FZM, Ziegemann PK, Rocha RO. Is there a best conventional material for restoring posterior primary teeth? A network meta-analysis. Braz Oral Res 2018; 32:e10. https://doi.org/10.1590/1807-3107bor-2018.vol32.0010

[11] Cajazeira MRR, Sabóia TC, Maia LC. Influence of the operatory field isolation technique on tooth-colored direct dental restorations. Am J Dent 2014; 27(3):155-9.

[12] Franzon R, Guimaraes LF, Magalhaes CE, Haas AN, Araujo FB. Outcomes of one-step incomplete and complete excavation in primary teeth: a 24-month randomized controlled trial. Caries Res 2014; 48(5):376-83. https://doi.org/10.1159/000357628

[13] Nyvad B, Baelum V. Nyvad criteria for caries lesion activity and severity assessment: a validated approach for clinical management and research. Caries Res 2018; 52(5):397-405. https://doi.org/10.1159/000480522

[14] Ekstrand KR, Bakhshandeh A, Martignon S. Treatment of proximal superficial caries lesions on primary molar teeth with resin infiltration and fluoride varnish versus fluoride varnish only: efficacy after 1 year. Caries Res 2010; 44(1):41-6. https://doi.org/10.1159/000275573

[15] Barmes D. Foreword for proceedings of the IADR symposium minimal intervention techniques for dental caries. J Public Health Dent 1996; 56(3):131-6.

[16] Trombelli L, Farina R, Silva CO, Tatakis DN. Plaque-induced gingivitis: Case definition and diagnostic considerations. J Clin Periodontol 2018; 45(Suppl 20):S44-S67. https://doi.org/10.1111/jcpe.12939

[17] Waggoner WF. Restoring primary anterior teeth: updated for 2014. Pediatr Dent 2015; 37(2):163-70.

[18] Goettems ML, Zborowski EJ, Costa FD, Costa VP, Torriani DD. Nonpharmacologic intervention on the prevention of pain and anxiety during pediatric dental care: a systematic review. Acad Pediatr 2017; 17(2):110-9. https://doi.org/10.1016/j.acap.2016.08.012

[19] Demarco FF, Collares K, Correa MB, Cenci MS, Moraes RR, Opdam NJM. Should my composite restorations last forever? Why are they failing? Braz Oral Res 2017; 31 (suppl 1):e56. https://doi.org/10.1590/1807-3107BOR-2017.vol31.0056

[20] Chisini LA, Collares K, Cademartori MG, de Oliveira LJC, Conde MCM, Demarco FF, et al. Restorations in primary teeth: a systematic review on survival and reasons for failures. Int J Paediatr Dent 2018; 28(2):123-39. https://doi.org/10.1111/ipd.12346

[21] Wang Y, Li C, Yuan H, Wong MC, Zou J, Shi Z, et al. Rubber dam isolation for restorative treatment in dental patients. Cochrane Database Syst Rev 2016; 9(9):CD009858. https://doi.org/10.1002/14651858.CDo09858.pub2

[22] Chadwick B, Treasure E, Dummer P, Dunstan F, Gilmour A, Jones R, et al. Challenges with studies investigating longevity of dental restorations - A critique of a systematic review. J Dent 2001; 29(3):155-61. https://doi.org/10.1016/s0300-5712(01)00003-3 